\title{
INTENTANDO CONSENSUAR CON FUTURAS PROFESORAS DE CIENCIAS LOS OBJETOS Y CRITERIOS DE SU EVALUACIÓN
}

\author{
Hugo, Diana V. ${ }^{1}$ y Sanmartí, Neus ${ }^{2}$ \\ ${ }^{1}$ Facultad de Ciencias de la Educación. Universidad Nacional del Comahue. Argentina \\ ${ }^{2}$ Departament de Didàctica de la Matemàtica i de les Ciències Experimentals. \\ Universitat Autònoma de Barcelona \\ hugodi@arnet.com.ar
}

\begin{abstract}
Resumen. La finalidad de este artículo es justificar la metodología utilizada en la formación inicial (y permamente) de profesores de ciencias que estamos aplicando en las prácticas profesionales. Se fundamenta en el uso de estrategias orientadas a compartir los objetos y criterios de evaluación entre la tutora-investigadora y los estudiantes, con la finalidad de aprender a autorregularse. También se presenta el análisis de las percepciones iniciales de ellos por parte de cuatro futuras profesoras que están aprendiendo a enseñar ciencias. Estas percepciones se comparan con las iniciales de la tutora-investigadora.
\end{abstract}

Palabras clave. Enseñanza de las ciencias, formación de profesores de ciencias, evaluación, autorregulación.

Summary. The purpose of this article is to justify the initial (and permanent) training methodology that we are applying to professors of sciences during their Training Practice. It is focused on the use of strategies aimed at sharing items and evaluation criteria between the tutor-researcher and the students so that the latter achieve self-regulation. On the other hand, it is to also to present the results of the analysis of four student's initial perceptions related to the objects and criteria that they are applying while they are learning how to teach sciences trough self regulation. These results are compared with the previous of the tutor-researcher.

Keywords. Science teaching, science professor training, evaluation, selfregulation.

\section{INTRODUCCIÓN}

La complejidad de la realidad social, interpersonal, personal y profesional en permanente cambio a la que deben dar respuesta actualmente los profesores al enseñar ciencias, así como la atención al inmenso caudal de conocimiento producido por la comunidad científica y tecnológica, demanda una capacitación permanente y el desarrollo de sus niveles más altos de autonomía en el aprender a enseñar.

En los últimos años se han realizado diversas investigaciones centradas en el desarrollo y aplicación -en la formación inicial y permanente del profesorado de ciencias-, de metodologías orientadas al desarrollo de su capacidad de autorregulación de concepciones y prácticas, como son, por ejemplo, las realizadas por el equipo de investigación de la Universidad de Monash (Australia)
(Baird et al., 1991; Gunstone et al., 1993; Lederman et al., 1994; Gunstone y Northfield, 1994; Gunstone, 2000) y el de la Universitat Autònoma de Barcelona (Angulo, 1996, 2002; Angulo y García, 1996, 2001; Copello, 1998; Sanmartí, 2000, 2001; Copello, Sanmartí, 2001; Hugo, 1998, 2000; Lucio, 2002). Estas investigaciones muestran resultados respecto al aumento de la autonomía de los profesores en la toma de decisiones a partir de la aplicación de estrategias de tipo metacognitivo.

En el marco de esta línea de trabajo y teniendo en cuenta una visión holística y compleja de la realidad, nuestra investigación pretende ir zanjando dicotomías que a menudo se plantean en la literatura y en la práctica educativa entre enseñanza y aprendizaje, enseñanza e investigación, reflexión y acción, desarrollo individual 
y trabajo grupal, cognición explícita e implícita, conocimiento cotidiano y científico, cambio y resistencia, teoría y práctica, evaluación y aprendizaje, cognición y afectividad, procesos conscientes e inconscientes, automáticos y controlados, metacognición y metaafectividad, a través de una convergencia de procesos de autoconocimiento. Particularmente nos interesa profundizar en el estudio de estas últimas, como problema y como posible respuesta a algunas de las dificultades que venimos observando en la formación de futuros profesores de química de la Universidad Nacional del Comahue (Argentina), en las asignaturas Didáctica de las Ciencias y, muy especialmente, en el de Prácticas Docentes de los futuros profesores de química. Algunas de estas dificultades son:

- La gran fragmentación y disociación de saberes que tienen, fruto sin duda de los planes de formación pero también de una tendencia a considerar que cada problema tiene una solución-receta posible.

- La persistencia en su pensamiento, de representaciones atomizadas y no coherentes respecto a la visión de ciencia, de enseñanza, de aprendizaje, de evaluación y también de los contenidos a enseñar.

- La necesidad de atender a la diversidad que presentan en cuanto a intereses, experiencia laboral, títulos previos y niveles de apropiación de las innovaciones didácticas.

- El escaso desarrollo del «saber hacer» o componente dinámico (Mellado et al., 1999) propio de un profesor de ciencias.

Tratando de encontrar respuestas superadoras a tal diagnóstico, venimos formando a los futuros profesores de química a través de una metodología de corte constructivista e investigativo basada en la reflexión sobre su propia práctica y su propio proceso de aprender a enseñar, potenciando, entre otros, el desarrollo y uso de estrategias metacognitivas y metaafectivas relacionadas con la evaluación formadora.

En el contexto de sus estudios, las Prácticas Docentes es una asignatura de la que se les evaluará y, como es sabido, la evaluación juega un papel muy importante en la representación de aquello que es importante aprender y, consecuentemente, en la autorregulación. Así planteamos la hipótesis, de acuerdo con Nunziati (1990), de que la representación por parte de los estudiantes, en nuestro caso futuros profesores de ciencias, de los objetos y criterios de evaluación del profesor favorece la autogestión de sus dificultades y dudas y, al mismo tiempo, potencia su transferencia a prácticas de enseñanza fundamentadas con el consiguiente desarrollo de la capacidad autorreguladora del alumnado. Pero no hay que olvidar que, simultáneamente, la evaluación genera sentimientos y emociones que pueden afectar al propio proceso de toma de conciencia y de autorregulación, por lo que también será importante incidir en todo lo relacionado con los aspectos metaafectivos.

Por todo ello, el primer objetivo de este artículo es jus- tificar el modelo de formación inicial (y permanente) de profesores de ciencias que aplicamos durante sus prácticas docentes, especialmente con relación al uso de estrategias orientadas a compartir, tutora-investigadora y estudiantes, los objetos y criterios de evaluación de la asignatura. El segundo es presentar los resultados del análisis de las percepciones iniciales de 4 alumnas en relación con los objetos y criterios a aplicar en la evaluación de sus Prácticas Docentes, comparándolos con los previos de la tutora-investigadora a fin de generar cambios en las mismas.

\section{FUNDAMENTACIÓN DE LA AUTORREGU- LACIÓN METACOGNITIVA Y METAAFEC- TIVA COMO ESTRATEGIA A PRIVILEGIAR EN LA FORMACIÓN DEL PROFESORADO}

En esta primera parte del artículo analizamos algunos de los puntos del debate actual sobre el aprendizaje y la formación docente relacionados con la conceptualización de la metacognición y la autorregulación como estrategias dinamizadoras de los procesos de cambio. Particularmente, nos interesa establecer relaciones con la evaluación y la afectividad, factores que valoramos como importantes en todo proceso de formación. Partimos del supuesto de que enseñanza, aprendizaje y evaluación no se pueden separar, como tampoco los componentes cognitivos, los relacionados con el «saber hacer» y los afectivos, por lo que nos interesa analizar dichas interrelaciones y justificarlas en relación con nuestra práctica de formación de formadores planteada en la asignatura Prácticas Docentes.

\section{Relaciones entre metacognición y aprender a ense- ñar ciencias}

En la literatura especializada sobre metacognición (Flavel, 1976, 1987; Garner, 1987) encontramos que existen varias acepciones del término, aunque en todos los casos se coincide en la existencia de dos componentes diferentes pero interrelacionados:

- Conocimiento de la cognición. Se refiere al conocimiento de un sujeto acerca de su propio funcionamiento cognitivo como aprendiz, de la cognición en general, de los factores que influencian su actuación y de sus productos cognitivos.

- Control de la cognición. Se asimila a un conjunto de procesos de supervisión y regulación que ejerce un sujeto sobre su actividad cognitiva cuando se enfrenta con una tarea. Ayudan, precisamente, a lograr el control consciente de los aprendizajes y van configurando un nuevo tipo de conocimiento, el conocimiento-saber metacognitivo relacionado con el primer componente.

Es metacognitivo «cuando existe un compromiso consciente con un enfoque informado y autodirigido, para reconocer, evaluar y decidir si se reconstruyen las propias ideas y creencias»(Gunstone, 1994, p. 133). 
La visión de «compromiso consciente» creemos que es importante porque implica a las finalidades de la actividad de aprender y al propio proceso. También consideramos que es importante la que relaciona este compromiso con «un enfoque informado», en el sentido de que el comportamiento metacognitivo que interesa es aquél que se relaciona con marcos teóricos, en nuestro caso el de la didáctica de las ciencias, como puede ser la relación entre metacognición y cambio conceptual.

En mayor o menor grado, las distintas propuestas de enseñanza de las ciencias han planteado la necesidad de desarrollar conocimientos metacognitivos para poder diferenciar entre conocimientos y prácticas cotidianas y científicas. Se destacan, por su carácter pionero, los planteamientos del proyecto australiano Project to Enhance Effective Learning -PEEL- (Baird y Northfield, 1992; White, 1999). Otras investigaciones sobre formación de profesores de ciencias, aunque centradas en la visión de «cambio conceptual» (Hewson et al., 1999), también se plantean, de hecho, una reflexión metacognitiva, ya que parten de la importancia de que los futuros profesores revisen sus ideas sobre la ciencia, sobre el aprendizaje y sobre cómo enseñarlas.

Otros estudios, como, por ejemplo, los relacionados con la comparación entre profesores expertos y novatos cuando enseñan a resolver problemas, muestran que las diferencias se deben no sólo a saberes cognitivos sino también metacognitivos (Swanson, 1990), al no saber que no se sabe. Además, parece ser que la capacidad para actuar «metacognitivamente» es altamente predictiva del éxito académico de los estudiantes y, cuando la tienen los profesores, la transfieren a sus alumnos (Gunstone et al., 1993; Gunstone y Mitchell, 1998). Por ello parece que es importante promover el desarrollo de esta capacidad en el profesorado, aumentando su control y compromiso consciente en relación con los conocimientos científicos a enseñar y los didácticos (Marcelo, 1994; Furió, 1994; Mellado, 1996).

\section{La autorregulación vista como proceso metacog- nitivo y metaafectivo}

En la reciente bibliografía aparece un considerable número de definiciones de «autorregulación» en aprendizajes formales y muchas veces con significados cercanos -cuando no análogos- al concepto de metacognición. En general, se considera la autorregulación como el estilo metacognitivo más importante cuyo uso asegura, en quien aprende, el logro de las metas que se ha propuesto (Butler y Winne, 1995). Se puede distinguir, pues, entre una autorregulación «inconsciente» (por ejemplo, la que aplicamos cuando aprendemos a caminar entre las rocas de una playa) y una consciente o metacognitiva.

El término autorregulación es empleado según cada autor en los sentidos autoinstrucción, autocontrol, autocuestionamiento, autodireccionalidad, automotivación, control emocional y de la acción, autogestión o autoevaluación (Zimmerman y Shunk, 1989; Nunziati, 1990;
Corno, 1994; Boekaerts, 1995; Butler y Winne, 1995; Kehr et al., 1999), pero el común denominador en todos los casos es el de promover la autonomía en la iniciación, la realización y la revisión de las propias acciones (Deci y Ryan, 1985).

Nos interesa destacar especialmente los trabajos que relacionan la autorregulación con la aplicación de estrategias metaafectivas, como las relacionadas con el control de las emociones y de la motivación, que posibilitan, por ejemplo, iniciar y sostener el tiempo y esfuerzo que demanda el aprendizaje autorregulado (Lindner y Harris, 1992; Boekaerts, 1999). Una característica de dicho aprendizaje es la implicación del alumnado en la selección de metas automotivadas de acuerdo con sus intereses, deseos, necesidades, expectativas y autovaloraciones, por lo que, sin la toma de conciencia y control de cómo estos condicionamientos influyen en nuestro aprendizaje, será difícil que se pueda hablar de aprendizaje autorregulado.

Se considera que, al iniciar un nuevo aprendizaje, la persona tiende a autorregular sus dificultades de forma mucho más consciente que cuando la acción ya se ha automatizado (Brown, 1987). Los ejemplos más habituales son los relacionados con aprender a conducir o a utilizar un programa de ordenador. Una vez se ha automatizado -convertido en rutina- la actividad es mucho menos costosa, pero tomar conciencia de las operaciones que se realizan y cambiarlas también es mucho más difícil. Ello es importante en la formación de profesores, ya que, como todos han sido alumnos durante muchos años de su vida, tienen interiorizado un modelo de enseñanza de las ciencias generalmente cercano al «tradicional». Ello implica que su aprendizaje se relaciona con la desautomatización de su propio modelo y, a su vez, con el aprendizaje del nuevo que se les presenta (Angulo, 2002).

Consecuentemente, las implicaciones afectivas de este aprendizaje son mucho mayores que las que se tienen cuando se aprende algo totalmente nuevo (al menos en sus fases iniciales). Lo que los futuros profesores han de aprender pone en cuestión puntos de vista muy relacionados con vivencias, actitudes, expectativas, motivaciones y autorepresentaciones, por lo que sin una autorregulación de este campo parece difícil que puedan autorregular sus ideas y prácticas.

\section{Autorregulación y evaluación formadora}

De acuerdo con Nunziati (1990), la autorregulación no se puede separar de la evaluación. Un estudiante se autorregula cuando toma conciencia de sus dificultades (y aciertos), las gestiona y toma decisiones acerca de posibles nuevas formas de pensar y también de actuar. En el aprendizaje, no es el profesor quien regula («corrige») sino el propio alumno. Por ello, la perspectiva de evaluación que puede tener sentido en el aula es la denominada evaluación formadora, superando las visiones dualísticas conflictivas entre regulación interna y externa y entre aprendizaje y evaluación. 
En esta perspectiva, Jorba y Sanmartí (1995) consideran que la autorregulación rompe con las clásicas divisiones entre enseñar, aprender y evaluar, jerarquizando la evaluación como el motor de todo el proceso de construcción de conocimientos. Para aprender es necesario, ante todo, construir un buen sistema personal de autocontrol y adquirir la mayor autonomía posible.

En nuestra propuesta de formación de profesores buscamos que la evaluación-regulación de los aprendizajes durante las Prácticas Docentes recaiga, fundamentalmente, en quien aprende, pues es el futuro profesor de química quien a través de la aplicación de estrategias autorregulativas debe encontrar las inconsistencias y disonancias entre los modelos de los que se habla en clase, los suyos propios y su práctica. Pero tal autocontrol no es sólo una actividad interna y pasiva sino que incluye, además, la toma de decisiones, el cambio. El aprendizaje autorregulado se genera hacia fuera, con el aporte del grupo, cuando la persona decide gestionar su actividad cambiando o modificando representaciones, vinculando saberes, comprometiendo comportamientos, conocimientos, marcos teóricos, prácticas, rutinas, intereses y emociones.

La evaluación formadora se vincula con la teoría de la actividad (Leontiev, 1989; Wertsh, 1981) en cuanto se plantea la evaluación-regulación de los componentes de toda actividad de aprender: los objetivos y motivos, los planes de acción, y los objetos y criterios de evaluación.

En este sentido, en relación con las estrategias promovidas desde la formación de profesores, consideramos importante llegar a compartir con el alumnado los $o b$ jetos y criterios de su evaluación porque creemos que a través de ellos se explicitan también los objetivos de la actividad y los planes de acción. De hecho, al discutir qué se va a evaluar, se está reflexionando sobre qué es importante saber y saber hacer para enseñar ciencias. No hay duda de que el docente tiene sus propios objetos y criterios, pero valoramos como necesario el proceso de transparencia que implica ponerlos a discusión e incluso cambiarlos si en el intercambio de pareceres surgen otros significados.

En la asignatura Prácticas Docentes, los objetos de evaluación se relacionan con la pregunta: ¿Qué aspectos se habrían de evaluar en la actividad de planificación y aplicación de una unidad didáctica? Responder a esta pregunta implica reconocer aspectos diferenciados en una actividad que, como la de enseñar ciencias, es compleja y en la que todos los factores se dan de forma interrelacionada. El tomar consciencia de dicha diversidad posibilita darse cuenta de su complejidad, superar puntos de vista simplistas y orientar la mirada hacia lo que se percibe como más relevante. Al mismo tiempo, implica reconocer la coherencia de estos objetos con el marco teórico en el que se van formulando.

Los criterios de evaluación responden a: ¿Cómo podremos reconocer si estamos diseñando y aplicando procesos de enseñanza de las ciencias que tengan en cuenta los objetos-aspectos identificados como importantes? Al reflexio- nar sobre los criterios de evaluación, se pone el acento en las estrategias de control que aseguran el cumplimiento de los objetos desde una dimensión autorreguladora fundamentada en la metacognición.

La finalidad es construir procedimientos para poder valorar la coherencia entre las ideas y la práctica, procedimientos que por ellos mismos también han de ser coherentes con dichas ideas, y todo ello en el marco de una concepción investigadora de la práctica docente (Porlán et al., 2001). Es evidente que el aprendizaje de la profesión requiere la aplicación de muchas otras estrategias además de la de compartir objetos y criterios de evaluación, pero consideramos que a través de ellos se sintetiza la representación que se tiene de las características asociadas al ejercicio de la profesión y que su análisis promueve puntos de vista (y prácticas) sobre la evaluación distintos de los conocidos y vivenciados.

\section{Autoevaluación, autorregulación y metaafectividad}

Uno de los mayores retos que afrontan los educadores tiene que ver con el hecho de que los estudiantes que alcanzan pocos logros carecen de referentes que orienten el autocontrol y, como resultado, subestiman la necesidad de alterar sus métodos de estudio o de trabajo (Gahtala et al., 1989). Aunque se hayan introducido referentes teóricos e incluso prácticos, generalmente estos alumnos no se representan ni los objetivos de su aprendizaje ni los objetos y criterios con los que se les evaluará, por lo que carecen de significado. Paralelamente, el profesorado no es consciente de la necesidad de comunicarlos y compartirlos, por lo que acostumbran a formar parte del conjunto de implícitos que se dan en el aula.

Por ello, el modelo de aprendizaje autorregulativo que estamos justificando requiere un cambio profundo en las concepciones del profesorado sobre la evaluación y, muy especialmente, sobre la necesidad de compartir con los que aprenden todo aquello que habitualmente se considera que compete sólo a los que enseñan. Más importante que evaluar resultados es evaluar los objetos con los que analizar la planificación de la actividad de aprender y los criterios puestos en juego en los mismos.

Consideramos que, para favorecer la construcción de un modelo personal de acción, es necesario que los estudiantes aprendan a verse a sí mismos en función de los aspectos que objetivizan planteamientos teórico-prácticos de la didáctica de las ciencias en cuya lógica se están introduciendo. El autocontrol da información sobre el estado en que se encuentran sus conocimientos a la hora de evaluarlos y la autorregulación permitirá modificar ese estado, iniciando o continuando alguna acción (Nelson y Narens, 1990, 1994). Al mismo tiempo, al analizar la calidad y pertinencia de sus actuaciones en función de lo que han planificado y anticipado, se posibilita que vayan interiorizando esos objetos y criterios. A largo plazo pueden actuar como metas flexibles y abiertas de su futura tarea docente, en procedimientos de control automático de ese aprender a enseñar ciencias que dura toda la vida profesional. 
Sin embargo, la evaluación está fuertemente interre-lacionada con factores afectivos. El reconocimiento de aspectos mejorables en nuestras actuaciones conlleva siempre el despertar de un conjunto de emociones que pueden interferir o favorecer el proceso de autorregulación cognitiva, ya que, tal como afirma Zimmerman (1999), los procesos autorregulatorios son cíclicamente interdependientes. Estas emociones, descritas de forma diferente según las líneas de investigación (Bisquerra Alzina, 2000), son reacciones a las informaciones que recibimos en nuestras relaciones con el entorno y se generan en función de evaluaciones subjetivas que realizamos sobre cómo dichas informaciones van a afectar a nuestro bienestar.

Por todo ello, incorporamos, a la discusión sobre los objetos y criterios de evaluación, la explicitación y el análisis de las emociones que el estudiante vivencia mientras evalúa-reflexiona sobre su proceso de aprender a aprender a enseñar ciencias. Buscamos, desde nuestro modelo holístico, que exterioricen esas emociones que acompañan a la valoración de sus expectativas o de sus actuaciones. La finalidad es que las reconozcan como algo normal, que se puede llegar a controlar, pues de la calidad, intensidad y cambio de las mismas dependerá, entre otros, el éxito en el aprendizaje y el ejercicio de la profesión. Al mismo tiempo, se persigue que valoren la importancia de tenerlas en cuenta en el aprendizaje de sus alumnos.

\section{Autorregulación, interacción social y afectividad}

Cuando un futuro profesor o profesora comienza a autoevaluarse o autorregularse no lo hace solo ni independientemente del contexto social que le rodea. La autorregulación rompe, también, con posibles visiones dualísticas conflictivas entre lo individual y lo social, ya que se va evolucionando a partir de las interrelaciones que establecen los futuros profesores entre sí y con otros profesionales. A través de estas interacciones con otros que también se están autorregulando, se van compartiendo elementos para reflexionar y así se va tomando consciencia de marcos teóricos y prácticos diferentes a los propios.

Los escritos de Vigotsky y sus continuadores fundamentan teóricamente el valor de la interacción en el aprendizaje. La visión de que el conocimiento se construye primero desde el punto de vista social para luego pasar a ser interiorizado conlleva que el grupo con el que se aprende sea un factor determinante. No sólo son importantes las capacidades de los que aprenden sino la posibilidad de desarrollarlas por la actuación de profesores y compañeros en su zona de desarrollo próximo. En este sentido, en nuestra propuesta de trabajo se ha buscado potenciar la interiorización de los objetos y criterios de evaluación a partir de que las futuras profesoras expliciten los propios puntos de vista, los compararen y los negocien con los de sus compañeras y con los de la tutora-investigadora.

El ejercicio de la profesión es complejo y no hay recetas que prefijen cuál es la mejor representación de lo que es ser un buen enseñante de química. Cualquier visión es provisional y, aunque se quiera evitar, parcial. Sin embargo, tampoco se puede suponer que «todo vale», ya que hay marcos teóricos que están más avalados que otros por la investigación didáctica. A través de la negociación de los objetos y criterios de evaluación se persigue, pues, llegar a compartir significados (Edwards y Mercer, 1987) sobre aspectos relacionados con la práctica profesional y evitar así que se los considere como preestablecidos. Estos significados se habrán de ir transformando, dinámicamente, con el aporte de todos y, a la vez, se irán convirtiendo en algo útil para el control no sólo del diseño que hagan de la unidad didáctica, sino también del de su aplicación. Consideramos que a medida que vayan interiorizando los objetos y criterios de evaluación, no como algo finalista e intocable sino como referentes para la reflexión, las alumnas podrán ir siendo cada vez más capaces de autocontrolar su propio proceso de cambio.

Pero, para que esta interacción pueda favorecer el aprendizaje, se necesita que el grupo priorice la cooperación frente a la competencia, que se acojan y valoren todos los puntos de vista, no sólo los relacionados con el conocimiento profesional, sino también con las actitudes hacia el cambio, la autopercepción y las creencias (Pintrich et al., 1993). En la evolución de las concepciones y de las prácticas no se puede olvidar la función de los factores afectivos y contextuales, ya que, para llegar a aceptar que el «error es el punto de partida para aprender» (Astolfi y Paterfalvi, 1997), se necesita no sólo ser capaz de autogestionar las ideas, sino también las emociones que se generan al reconocer que no se sabe.

Si bien hay acuerdo en que la participación y la mirada de muchos tiende a enriquecer el aprendizaje y a disminuir la resistencia al cambio que manifiestan buena parte de los futuros profesores, también es cierto que, para que estas interacciones sean fructíferas, es necesario que se establezcan relaciones de colaboración fundamentadas en el respeto mutuo.

\section{Autorregulación y cambio}

La enseñanza de las ciencias depende de las representaciones del saber académico específico que se tiene, que muchas veces está influido por las representaciones implícitas e inconscientes del profesorado sobre ciencia, aprendizaje y sobre métodos de enseñanza, a las que añadiríamos las concepciones sobre evaluación (Sanmartí, 2000). Hewson y otros (1999) proponen llamar a este conjunto de representaciones concepciones de la enseñanza de la ciencia en tanto en cuanto son concepciones respecto a dichos aspectos construidas a partir de sus interrelaciones, que constituyen, en muchos casos, verdaderos obstáculos epistemológicos (Porlán et al., 1997).

Por otro lado, también dependen de las rutinas y los guiones de acción (Porlán et al., 1997) aprendidos a través de la experiencia previa como alumnos. Todos los futuros profesores han sido durante muchos años estudiantes que han aplicado formas de aprender promovidas por sus profesores (o familiares), y han convertido en rutinarias formas de actuación que requieren muy poco esfuerzo. 
También es importante tener en cuenta el componente ideológico relacionado con los valores personales y las creencias sobre la importancia, la utilidad y el interés de una idea o tarea. Muchos de los grandes temas a debate en la enseñanza de las ciencias, como, por ejemplo, la enseñanza para todos los alumnos teniendo en cuenta su diversidad o los contenidos a priorizar en relación con las temáticas transversales, no se pueden plantear al margen de compromisos ideológicos.

Desde los planteamientos constructivistas de la enseñanza-aprendizaje se está de acuerdo en que la formación de profesores requiere un cambio conceptual y un cambio «en»-0, mejor, «sobre»- las prácticas, y que estos dos cambios estén interrelacionados.

Una de las fuentes de todo cambio es la toma de decisiones de manera explícita, comprometida, consciente, informada y autodirigida en función de unas metas. Tales decisiones pueden surgir de tomar conciencia de la insatisfacción o contradicción entre las propias ideas, creencias, concepciones o prácticas frente a las nuevas que se están aprendiendo, y de reconocer, evaluar y decidir si se van a reconstruir a través de autorregular sus propuestas de acción, seleccionando los contenidos curriculares y las estrategias más apropiadas al grupo de alumnos y al contexto en el que se trabaja.
Por lo tanto, los cambios activan en el futuro profesor los saberes «meta» que se van adquiriendo a través de estrategias metacognitivas, de autorregular cómo se toma conciencia y controla el propio proceso de cambio (Gunstone y Northfield, 1994) en relación con lo que hacen y piensan otros compañeros o compañeras.

Pero Pintrinch y otros (1993) afirman que los cambios metacognitivos no se pueden separar de los metaafectivos; es decir, de los cambios en la autopercepción sobre uno mismo y de las propias capacidades para enfrentar con éxito o no la tarea de enseñar; de las propias emociones y sentimientos derivados de la ejecución de la misma; y de las atribuciones causales que se realizan ante los resultados que se van obteniendo mientras se aprende a enseñar.

El cambio conceptual, afectivo y de la práctica no es puramente el resultado de un proceso racional llevado a cabo individualmente, sino que depende de cómo el que aprende se ve y se «siente» a sí mismo en relación con los demás; en este caso, en relación con los compañeros (de estudio o de trabajo), con el profesor y con los alumnos a los que se pretende enseñar. Requiere, además, distinguir las demandas que presupone el rol que le corresponde como aprendiz y como docente al enseñar ciencias (Monereo y Badía, 1997), así como la vinculación que existe entre ambos contextos.

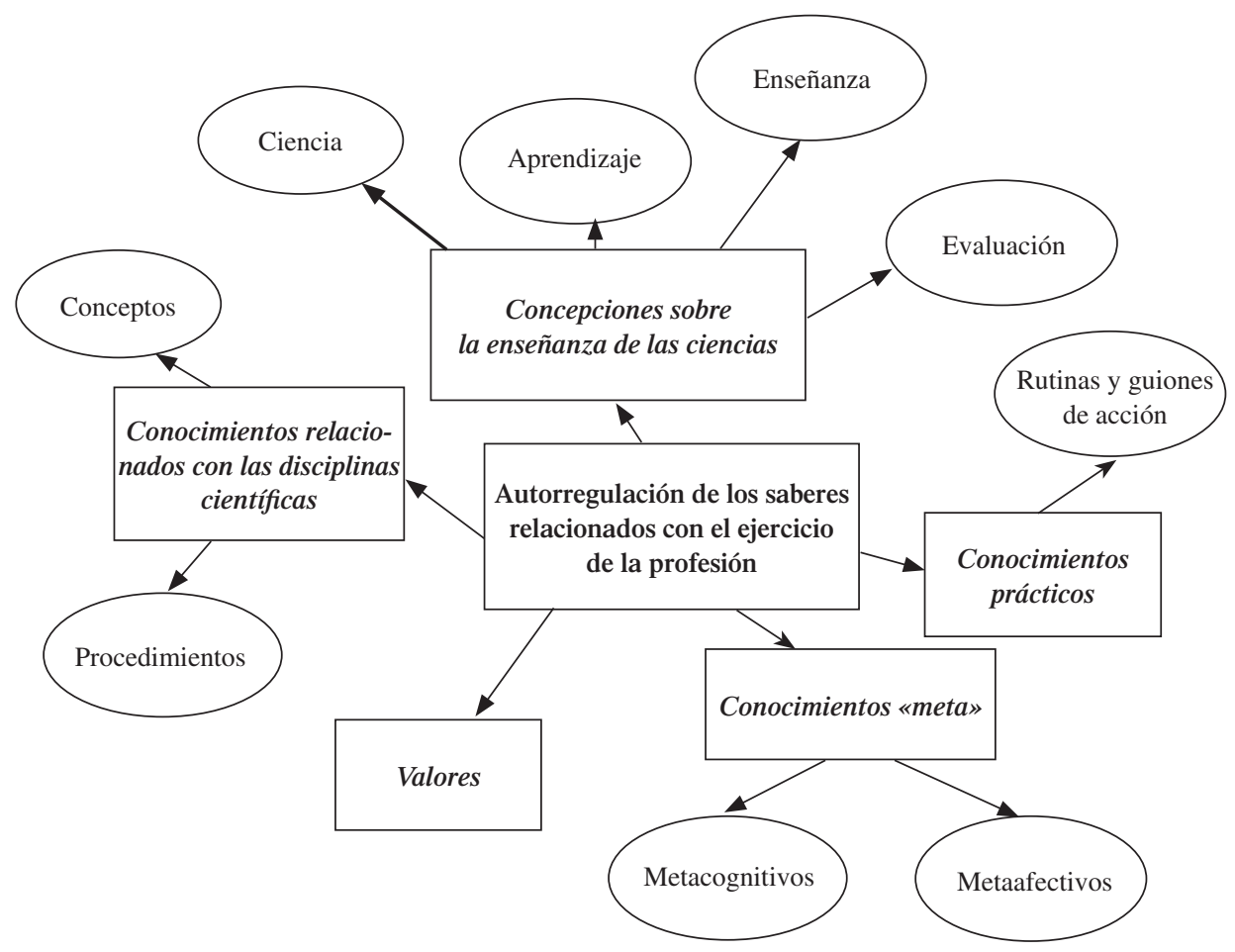


En nuestra experiencia realizada en el marco de la asignatura Prácticas Docentes, hemos escogido incidir en compartir los objetos y criterios de evaluación porque creemos que es una opción que posibilita profundizar de forma holística en el conjunto de aspectos recogidos en la figura 1. Sin duda es una opción entre las posibles pero la hemos valorado como válida teniendo en cuenta el poco tiempo del que se dispone para actuar sobre los procesos de cambio de los futuros profesores. Como ya se ha indicado, los objetos y criterios de evaluación recogen los saberes cognitivos relacionados con la acción que el profesorado prioriza, pero al mismo tiempo a través de ellos se evidencian las autopercepciones y creencias sobre uno mismo y sobre los demás. Y paralelamente se incide en especial en el cambio de las representaciones y de las prácticas en un campo -el de la evaluación- con gran carga ideológica y afectiva, que habitualmente forma parte sólo del currículo oculto tanto en la formación del profesorado como en la de los propios alumnos en las clases de ciencias.

La reflexión mediada por el lenguaje (oral y escrito) sobre dichos objetos y criterios de evaluación, así como su discusión y negociación en el seno de un grupo, conlleva una primera toma de conciencia de los mismos y toma de decisiones desde el punto de vista de las representaciones cognitivas. Este marco-guía se constituye en referente para reflexionar sobre el diseño de la unidad didáctica y sobre su aplicación, configurando los llamados esquemas prácticos de acción en el aula o el componente profesional dinámico (Gess-Newsome y Lederman, 1993; Tobin, 1993; Mellado, 1996; Mellado et al., 1999). Y al mismo tiempo, es el marco desde el cual analizar y reconstruir tanto pensamientos pesimistas que generan emociones negativas (miedo, ansiedad) tendentes a obstaculizar el aprendizaje, como otros más positivos (sensación de desafío, de confianza) que llegan a impulsarlo.

\section{OBJETIVOS DE LA INVESTIGACIÓN E INS- TRUMENTOS DE RECOGIDA DE DATOS}

La investigación que estamos desarrollando se propone estudiar las representaciones de profesoras en formación acerca de los objetos y criterios de evaluación de sus prácticas docentes, cómo las van variando a lo largo de ellas, cómo se correlacionan con la planificación de la unidad didáctica que diseñan y con su aplicación y, finalmente, cómo las tienen en cuenta en las reflexiones explicitadas en la memoria final de su trabajo.

En este artículo sólo se analizan las representaciones iniciales de cuatro alumnas, recogidas a través de los siguientes instrumentos:

- Escrito en el que habían de explicitar su visión de una «buena enseñanza de las ciencias».

- Resultados de la negociación entre parejas de alumnas o díadas de los aspectos sobre los que opinaban que deberían ser evaluadas, así como de los criterios de evaluación (Anexo I). Esta negociación se realizó después de haber reflexionado y escrito primero individualmente sus puntos de vista.

- Resultados de la comparación-negociación de los mismos con los propuestos por la tutora-investigadora, realizada con la finalidad de consensuar una representación inicial.

\section{MUESTRA}

La investigación se desarrolló con un grupo de cuatro futuras profesoras de química del curso 1999 de la asignatura Prácticas Docentes, correspondiente al tramo final del Plan de Profesorado de Química de la Universidad Nacional del Comahue (Argentina), íntimamente relacionada con otra asignatura ya cursada anteriormente, Didáctica de las Ciencias. Una misma profesora, que en este estudio cumple el rol de tutora-investigadora universitaria, está al frente de ambas cátedras facilitándose la coherencia de criterios y la continuidad de prácticas.

Las alumnas realizaron sus prácticas docentes en un colegio semiprivado de la ciudad de Neuquen (Argentina), el cual se caracteriza por ser muy abierto a la implementación de innovaciones pedagógico-didácticas y por ofrecer a sus alumnos escoger en los últimos cursos de secundaria entre una orientación de humanidades o de exactas.

La muestra era representativa de la diversidad de estudiantes que se da año tras año en cuanto a intereses, resistencia al cambio, títulos o prácticas profesionales previas y tendencia a la innovación.

Las alumnas se agruparon espontáneamente por parejas, que en este trabajo llamamos díadas I y II. Cada díada tenía que trabajar en el diseño de una unidad didáctica con contenidos similares pero dirigidos a alumnos de distinta orientación. Las que calificamos de «expertas» son profesoras que ya tienen más de diez años de ejercicio en la docencia y un título previo afín aunque no necesariamente universitario. $\mathrm{La}$ tendencia hacia la innovación se distribuía en un continuo desde la más innovadora a la menos (Fig. 2). Las integrantes de la díada I se conocían mucho, no así las de la II.

Las actividades realizadas y los instrumentos aplicados para la recogida de datos fueron ya probados en una experiencia piloto (Hugo, 1998), algunos de cuyos resultados se tendrán también en cuenta en la discusión de los obtenidos en este trabajo.

\section{RESULTADOS: REPRESENTACIONES INICIA- LES SOBRE ASPECTOS A PRIORIZAR EN LA ENSENAANZA DE LAS CIENCIAS}

En este apartado se analiza:

- La visión inicial de enseñanza de las futuras profesoras. 
Figura 2

Cambios de la muestra.

\begin{tabular}{|c|c|c|c|c|c|c|c|}
\hline División & Orientación & Asignatura & $\begin{array}{c}\text { Unidad } \\
\text { asignada }\end{array}$ & Díada & Alumnas & Experiencias & $\begin{array}{l}\text { Carácter } \\
\text { innovador }\end{array}$ \\
\hline $\begin{array}{l}4^{\circ} \text { año } \\
(16 \text { años) }\end{array}$ & Humanidades & $\begin{array}{l}\text { Química } \\
\text { general }\end{array}$ & $\begin{array}{l}\text { P. químicas } \\
\text { hidrocarburos } \\
\text { Polímeros }\end{array}$ & \multirow{2}{*}{ I } & \multirow{2}{*}{$\begin{array}{c}\text { Analía } \\
\text { y } \\
\text { Mari }\end{array}$} & Experta & Alto + \\
\hline $\begin{array}{l}4^{\circ} \text { año } \\
(16 \text { años) }\end{array}$ & Exactas & $\begin{array}{l}\text { Química } \\
\text { general }\end{array}$ & $\begin{array}{l}\text { P. químicas } \\
\text { hidrocarburos } \\
\text { Polímeros }\end{array}$ & & & Experta & Alto - \\
\hline $\begin{array}{l}5^{\circ} \text { año } \\
(17 \text { años) }\end{array}$ & Humanidades & $\begin{array}{l}\text { Química } \\
\text { orgánica }\end{array}$ & $\begin{array}{l}\text { Ácidos } \\
\text { y bases }\end{array}$ & \multirow[b]{2}{*}{ II } & \multirow{2}{*}{$\begin{array}{c}\text { Josefa } \\
\text { y } \\
\text { Marcela }\end{array}$} & Novata & Bajo + \\
\hline $\begin{array}{l}5^{\circ} \text { año } \\
(17 \text { años) }\end{array}$ & Exactas & $\begin{array}{l}\text { Química } \\
\text { orgánica }\end{array}$ & $\begin{array}{l}\text { Ácidos } \\
\text { y bases }\end{array}$ & & & Experta & Bajo - \\
\hline
\end{tabular}

- Los objetos y criterios de evaluación explicitados por cada díada en comparación con los de la profesora.

\section{Puntos de vista iniciales de las futuras profeso- ras sobre la enseñanza}

Se han analizado los aspectos de la práctica docente que cada uno de los casos destaca en su escrito inicial. Se los ha relacionado con posibles visiones de enseñanza tradicionales o con otras más coherentes con planteamientos actuales, así como con la experiencia anterior en el ejercicio de la profesión.

- Caso Analía: Con varios años de experiencia en la tarea docente se muestra como la más innovadora, ya que prioriza en todo momento los aspectos relacionados con la comunicación profesor-alumno, incidiendo especialmente en el componente afectivo: apertura a escuchar a los chicos; paciencia, desde lo afectivo se consigue una buena comunicación; contenidos que les despierten interés, que los lleve a hacerse preguntas y a la búsqueda de respuestas; la comunicación docente-alumno desde el contenido $y$ desde lo afectivo. Ve la necesidad de lograr espacios comunes de entendimiento y significados compartidos: no se pueden establecer claramente canales donde el lenguaje no sea el mismo. También es innovador el criterio CTS que propone para seleccionar el contenido: contenidos que sean de utilidad, que les sirvan para interpretar los fenómenos de su vida, de su medio.

- Caso Marcela: También experta, aunque quizás la menos innovadora, responde desde una visión más tradicional de la enseñanza al centrar el eje del proceso de enseñanza-aprendizaje en el docente: conocer la ciencia que elegí... poniendo la energía para lograr que el alumno acceda a él. Esta estudiante también contempla aspectos afectivos pero desde un lugar más tradicional: intentando crear un clima agradable, para que los alumnos se sientan cómodos y me tengan confianza; respetando y haciéndose respetar; usando recursos para hacer más amena la experiencia y, sobre todo, más interesante. También Marcela hace alusión a los contenidos CTS: resaltar el lugar del conocimiento en la vida.

- Caso Mari: Coexiste en esta experta algún aspecto tradicional como la mención que hace a la exposición como técnica de enseñanza: conocer muy bien la asignatura que vamos a dictar y, a la separación entre teoría y práctica: hacer experiencias porque son útiles para observar lo que uno marca desde la teoría. Sin embargo también responde otorgando peso a los aspectos afectivos: querer lo que hacemos; relacionar los conceptos teóricos que damos con lo que el joven vive y sus propios intereses, al lenguaje y a la atención de la diversidad: elegir materiales para trabajar con el lenguaje apropiado para los grupos (acorde a edades y cursos). También contempla los contenidos CTS: humanizando la ciencia para acercarla a los alumnos.

- Caso Josefa: La única que no tiene práctica profesional, escatima a explicitar sus ideas, quizás porque la ausencia del componente dinámico de los profesores le impida hacer uso del conocimiento declarativo. Este punto de partida lo expresa a través de una metarreflexión acerca de sí misma: en mi caso, sin experiencia laboral en docencia, creo que la frase enseñaría mejor se traduce a ¿Cómo enseñarías...?; en el aula, la verdad, no sé cómo se hace. Sólo se arriesga a anticipar sus representaciones acerca del criterio CTS de selección de los contenidos: enseñar la ciencia como conocimiento útil, desde lo cotidiano... relacionándolo con hechos que le sean familiares al alumno.

En resumen, casi todas las alumnas mantienen, al iniciar las Prácticas Docentes, rasgos, en mayor o menor grado, propios de modelos tradicionales de enseñanza. De ello inferimos que los aportes teóricos y las escasas prácticas innovadoras que han vivenciado a lo largo de su formación no parecen haber incidido todo lo deseado en el cambio de sus representaciones. Con las respuestas de las expertas Mari y, fundamentalmente, Marcela 
podemos suponer que el desarrollo en las mismas del componente profesional dinámico no se relaciona necesariamente con puntos de vista más innovadores ni más centrados en el aprendizaje de los alumnos.

Todas hacen alusión a la importancia de enseñar conocimientos vinculados a las relaciones CTS, comprobando, al menos desde el discurso escrito, que este aspecto ha sido internalizado como una de las finalidades importantes de la educación científica actual.

Las expertas, quizás como producto del desarrollo del componente dinámico, destacan algunos de los aspectos del amplio campo afectivo como variables importantes a tener en cuenta al enseñar ciencias. También es interesante comprobar que unas redactan pensando fundamentalmente en el alumnado, mientras que las otras lo hacen pensando fundamentalmente en su actuación.

\section{Características de los objetos y criterios de eva- luación propuestos}

En este apartado se caracterizan los objetos y criterios de evaluación explicitados por las estudiantes después de negociarlos por parejas. Para ello realizamos un análisis comparativo entre los expresados por cada díada (Anexo I) con los de la tutora-investigadora inicialmente (Anexo II), tomando las siguientes categorías:

- Cantidad de objetos propuestos respecto a los de la tutora-investigadora A/16, en que $\mathrm{A}$ es el número de objetos propuestos por la alumna y 16 es el número total propuesto por la tutora.

- Objetos de la tutora-investigadora al que hace referencia cada díada. Se indican tomando como referencia el número del de la tutora.

- Criterios de evaluación de cada objetivo de la díada respecto a los de la tutora-investigadora. Aunque los objetos expresados por las díadas y por la profesora se pueden corresponder, al comparar los criterios de unas y la otra aparecen diferencias en su alcance (cantidad de aspectos considerados al explicitar cómo lograr el objetivo) o en la significatividad de los mismos (proceso subjetivo de dar sentido a cada objeto a través de los criterios de evaluación. Así pues, se han comparado los criterios expresados según sus características:

\section{Alcance}

- Igual. Mencionan prácticamente los mismos aspectos que la tutora-investigadora.

- Menor. Mencionan pocos aspectos respecto a los que propone la misma.

- Mayor. Mencionan más aspectos que la misma.

\section{Significatividad}

- Igual: Están redactados desde una visión constructivista de la enseñanza-aprendizaje.
- Distinta. Están redactados desde una visión tradicional.

- Jerarquización de un objeto de evaluación: Se ha perseguido valorar el posible grado de importancia que la díada da a un determinado objeto de evaluación, ya sea porque hace alusión a éste en distintos lugares (por repetición) o porque lo prioriza al escribirlo, por ejemplo, en primer lugar (por el orden).

\section{Objetos y criterios de evaluación de la díada I: Analía- Mari}

- Cantidad de objetos propuestos respecto a los de la tutora investigadora: $8 / 16$

- Objetos de la tutora-investigadora al que hace referencia la díada: núm. 1, núm. 2, núm. 3, núm. 5, núm.6, núm.7, núm.15, núm.16.

- Criterios de evaluación de cada objeto de la díada respecto a los de la tutora-investigadora:

- Objetos de distinta signicatividad y menor alcance: Ninguno.

- Objetos de igual significatividad y menor alcance:

Relación con los alumnos, que presenta dos criterios de evaluación, uno de ellos desde lo cognitivo, en la capacidad para motivar, despertar el interés se aproxima al núm. 5: Control de clase.

Selección de contenidos (el nivel de profundidad con que se desarrollan) con sus criterios que estén relacionados con la vida cotidiana y les sirva para interpretar los fenómenos que viven, lo vinculamos al núm. 15: Didáctica innovadora de las ciencias, aunque la tutora-investigadora cita muchos otros aspectos innovadores.

El material empleado con sus criterios que sea de lectura comprensible con ejercitación de acuerdo con sus capacidades; la complejidad que presente en la resolución de los trabajos, el que vinculamos al objeto núm. 3: Preparación del material, aunque la tutora-investigadora controla más aspectos en el diseño de los guiones didácticos.

El manejo del tiempo en la planificación con su criterio de evaluación de que los contenidos y actividades sean acordes al tiempo que se tiene se asemeja al núm. 1: Planificación, pero descuida otros aspectos de la misma.

- Objetos de igual significatividad y alcance:

Claridad conceptual en las explicaciones y lenguaje utilizado, que ayude a comprender lo que se habla y a enriquecer el que se tiene comparten sus criterios: en el desarrollo de la clase, en la interacción con los alumnos (la capacidad de generar preguntas en ellos y poder dar respuestas), que vinculamos al núm. 2: Conocimiento del tema, al núm. 6: Comunicación, al núm. 7: Capacidad para promover el diálogo profesor-alumno. 
- Objetos de igual significatividad y mayor alcance:

La autorregulación con su criterio si se logra que todos podamos controlar nuestros aprendizajes: ¿Qué y cómo aprendemos? el que asociamos al de la tutora-investigadora núm. 16: Autorregulación de su actuación, da muestras de haber internalizado la propuesta de aprender a enseñar por autorregulación y anticipa la necesidad de transferirla a sus alumnos, situación que no explicitó la tutora-investigadora.

Relación con los alumnos, el mismo objeto que antes pero con otro de sus criterios, desde lo afectivo, en el diálogo, en los gestos, en el clima que reine en el aula... el que asociamos al núm. 6: Comunicación, al núm. 7: Capacidad para promover el diálogo profesor-alumno, si bien la tutora-investigadora no contempló los aspectos afectivos en los mismos.

- Jerarquización de un objetivo:

- Por repetición: núm. 6: Comunicación y el núm. 7: Capacidad para promover el diálogo profesor-alumno.

- Según el orden en que presenta sus objetivos: La relación con los alumnos escrito en primer término acentuando en sus criterios de evaluación los aspectos afectivos.

\section{Objetos y criterios de evaluación de la díada II: Josefa- Marcela}

- Número de objetos de evaluación respecto a los de la tutora-investigadora: $8 / 16$.

- Objetos de la tutora-investigadora al que hace referencia la díada: núm. 1, núm. 3, núm. 4, núm. 5, núm. 6, núm. 10, núm. 13, núm.14.

- Criterios de evaluación de cada objeto de la díada respecto a los de la tutora-investigadora:

- Objetos de distinta significatividad y menor alcance:

Relación con los alumnos con su criterio de evaluación si logramos establecer una relación amena y respetuosa, de mutua confianza parecería vincularse al núm. 6: Comunicación.

Desarrollo de la clase con su criterio si conseguimos explicar claramente los contenidos utilizando correctamente el lenguaje y con ejemplos adecuados se acerca, aunque desde un modelo tradicional, al núm. 4: Gestión del aula.

Utilización del espacio y tiempo, con su criterio bastante impreciso, si administramos adecuadamente el escaso tiempo de una época y de cada clase se acerca, también, al núm. 4: Gestión del aula.

Cumplimiento de los objetivos propuestos con sus criterios si al final de la práctica logramos alcanzar los objeti- vos particulares de la unidad a desarrollar y los objetivos generales de la asignatura propuestos por la profesora titular se aproxima al núm. 13: Evaluación aunque parece que es el docente quien deba alcanzar los objetivos y además hace sólo referencia a la evaluación sumativa.

- Objetos de igual significatividad y menor alcance:

Creatividad y originalidad con su criterio de evaluación si el tipo de ejercitación, evaluación y actividades resultan atractivas y motivadoras para los alumnos que asociamos al núm. 14: Actitud global si bien la tutora-investigadora contempla además otros aspectos personales del futuro profesor y, parcialmente al núm. 5: Control de clase.

Estructuración de la unidad a innovar (guión) con sus criterios de evaluación, presentación, secuenciación, organización, claridad, profundidad en el tratamiento del tema y coherencia de las actividades que vinculamos al núm. 1: Planificación y al núm. 3: Preparación del material, en el que la tutora-investigadora alude también al guión didáctico pero como recurso didáctico que ayuda al control metacognitivo y motivacional de la enseñanza.

- Objetos de igual significatividad y alcance:

Utilización de los recursos con su criterio de evaluación si conseguimos manejar bien el espacio del pizarrón con expresiones legibles, ordenadas y prolijas, lo vinculamos al núm. 10: Uso del pizarrón. Posicionada en un modelo tradicional contempla sólo el pizarrón como recurso, olvidando otros que la tutora-investigadora detalla en el núm. 12: Uso de recursos audiovisuales.

- Objetos de igual significatividad y mayor alcance: Ninguno.

- Jerarquización de un objeto:

- Por repetición: núm. 4: Gestión del aula.

- Según el orden en que presenta sus objetos: Relación con los alumnos, al igual que la díada I, lo coloca en primer término jerarquizando los aspectos afectivos aunque con distinta intencionalidad.

\section{Comparación de los objetos y criterios de eva- luación de las dos díadas}

En la figura 3, donde se muestra el análisis comparativo entre las dos díadas, se puede comprobar que inicialmente la díada I respecto a la II refleja, a través de los criterios de evaluación explicitados, un mayor acercamiento a los de la tutora.

\section{Número de objetos de evaluación}

Ambas díadas citan un número menor que el propuesto por la tutora-investigadora quizás porque aún persista uno de los obstáculos del pensamiento del profesor como lo es la tendencia a la simplificación y al reduccionismo (Porlán et al., 1997). 
Figura 3

Gráfico comparativo de las díadas I y II.

Comparación de los objetos y criterios de evaluación de las dos díadas

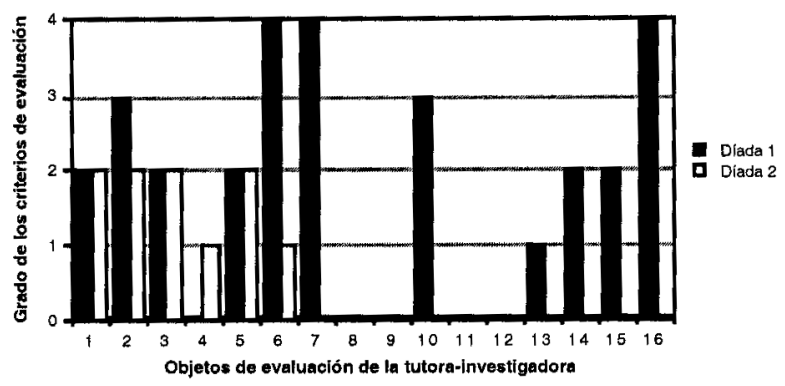

- Grado de los criterios de evaluación en comparación con los de la tutora: 1. Distinta significatividad y menor alcance. 2. Igual significatividad pero menor alcance. 3. Igual significatividad y alcance. 4. Igual significatividad pero mayor alcance

- Objetos de evaluación de la tutora: 1. Planificación. 2. Conocimiento del tema. 3. Preparación del material. 4. Gestión del aula. 5. Control de clase. 6. Comunicación. 7. Capacidad de promover el diálogo profesor - alumno. 8. Atención a la diversidad. 9. Visión globalizada de la actividad educativa. 10. Uso de pizarrón. 11. Capacidad de organizar el trabajo experimental. 12. Uso de recursos audiovisuales y TIC. 13. Evaluación. 14. Actitud global. 15. Didáctica innovadora. 16. Autorregulación de su actuación.

\section{Objetos de la tutora-investigadora a los que hacen refe- rencia las dos díadas}

- Núm. 1; núm. 3; núm. 5; núm. 6.

Los objetos a los que ninguna de las dos díadas hace referencia son:

- Número 8: Atención a la diversidad, quizás por la presencia de otro obstáculo, como la tendencia a pensar en el grupo clase en cualidad de grupo homogéneo (Porlán et al., 1997) o porque se refleje una de las carencias del sistema educativo de no atender en sus aulas la diversidad que las mismas presentan.

- Número 9: Visión globalizada de la actividad educativa probablemente porque, al estar formándose como profesoras de una disciplina, les cuesta reconocer la necesidad de un trabajo en equipo de todo el profesorado y de relacionar lo que se aprende en una disciplina con otras.

- Número 11: Capacidad para organizar el trabajo de laboratorio. Parece extraño que no hagan alusión al mismo. La lectura de este dato puede ser positiva, si dicha actividad está considerada como un tipo más de actividad en el proceso constructivo de la ciencia escolar, rompiendo barreras entre teoría y práctica. Pero también puede ser negativa si no se valoran los trabajos prácticos como fundamentales en la enseñanza de las ciencias.

- Número 12: Uso de recursos audiovisuales. Creemos que, implícitamente, los incluyen al referirse a los guiones didácticos.

\section{Criterios de evaluación para cada objeto de ambas díadas respecto a los de la tutora-investigadora}

- Objetos de distinta significatividad y menor alcance: núm. 4, núm. 6 y núm. 13, todos aportados por la díada II, lo que muestra diferencias de partida importantes entre una y otra.

- Objetos de igual significatividad y menor alcance: núm. 1 , núm. 3 y núm. 5 , aportados por ambas díadas; núm. 14 , por la díada II; y núm. 15 , por la I, considerado más relevante que el anterior.

- Objetos de igual significatividad y alcance: núm. 2, aportado por la díada I, y núm. 10, por la II, entendiendo que el propuesto por esta última es, también aquí, menos relevante que el de la I.

- Objetos de igual significatividad y mayor alcance: núm. 6 , núm. 7 , núm. 16, aportados por la díada I, indicándonos de nuevo que el punto de partida de ésta es mejor.

\section{Jerarquización de un objeto}

- Por repetición: núm. 4, repetido por la díada II; núm. 6 y núm. 7, por la I, pero sólo los de esta última son expresados de manera similar a la tutora-investigadora. Ambas díadas están preocupadas por el control del tiempo, lo que es razonable debido al poco de que disponen para sus prácticas y porque perciben la dificultad de preverlo en el desarrollo de las distintas actividades.

- Según el orden en que presenta sus objetos: Relación con los alumnos es citada en primer término por ambas díadas, jerarquizando los aspectos afectivos, aunque sólo la I la entiende para comunicarse y enseñar-aprender mejor.

\section{Interacciones puestas en juego en los procesos de nego- ciación intradíadas}

Al fin de analizar si hubo cesión de intereses, estudiamos cómo se dieron las contribuciones de las integrantes dentro de cada díada al negociar los objetos y criterios aportados por cada una. Para ello comparamos las representaciones iniciales de cada futura profesora sobre la buena enseñanza con los objetos y criterios de evaluación que llegaron a consensuar con el otro integrante de su díada (Anexo I). Así llegamos a las siguientes conclusiones:

- Díada I: De expertas, se tomaron en cuenta las contribuciones de ambas integrantes. Más aún, Mari y Analía se apropiaron mutuamente de las comprensiones respectivas logrando que, en la negociación, se reconstruyeran ideas tradicionales, como, por ejemplo, la disociación teoríapráctica, que inicialmente puntualizaba Mari: $\mathrm{Ha}$ cer experiencias porque son útiles para observar lo que uno marca en la teoría. Además se reorganizaron otras ideas como las de Analía y Mari sobre la comunicación en un nuevo objeto innovador, como, 
por ejemplo, la relación con los alumnos jerarquizando los aspectos afectivos, o bien surgieron nuevas ideas tan innovadoras como la autorregulación, con un alcance aun superior al que le dio la tutorainvestigadora.

- Díada II: Prosperaron las ideas más tradicionales de Marcela, experta, como crear un clima agradable para que los alumnos se sientan cómodos y me tengan confianza, respetando y haciendo respetar, que conformaron el objeto «relación con los alumnos», dejando atrás la valiosa propuesta hecha por la novata Josefa: enseñar la ciencia lo más asequible posible relacionándola con hechos familiares al alumno (entorno geográfico, socioeconómico y productivo). Creemos que en esta negociación hubo cesión de intereses de Josefa, producto quizás de la relación asimétrica de poder determinada por el desarrollo de la experiencia como docente de Marcela.

\section{La negociación tutora-alumnas}

Una vez las alumnas hubieron concretado por parejas sus propuestas de objetos y criterios de evaluación, la tutora-investigadora les dio a conocer lo que ella había diseñado inicialmente sin conocer lo que las alumnas habían propuesto. Ello se hizo con la finalidad de «ser transparente» y poder compararlos, discutirlos y cambiarlos en función de lo que fuera acordado entre la tutora y las alumnas. Sin embargo, éstas consideraron que la propuesta de la tutora ya era buena para ser considerada como la válida y no se atrevieron a valorarla.

Aunque la variable «tiempo» influyó en este hecho (la actividad se realizó en el tramo final de la clase), constatamos una vez más la dificultad de poner en discusión aspectos de la vida de clase que se relacionan con la autoridad del profesorado. Los estudiantes dan por hecho que éste es un campo en el que no conviene discutir (a no ser que el desacuerdo sea muy grande), especialmente porque a través de él se concreta el poder de decidir sobre su futuro profesional.

Algunas de las causas que, probablemente, hicieron callar la voz de las estudiantes y delegar la responsabilidad se relacionan con no asumir aún la importancia de aprender por autorregulación, con el miedo a hablar y a contradecir la propuesta bien sistematizada presentada por la profesora o quizás a la falta de costumbre en participar de algo tan privativo del docente como es la evaluación.

Valoramos, pues, la necesidad de incidir más en aspectos de la vida del grupo que promuevan el cambio del «contrato didáctico» que implícitamente se establece (Joshua y Dupin, 1993). En este caso, fue la tutora la que modificó sus objetos y criterios, incorporando aspectos manifestados por la díada I. Así, en el núm. 7, Capacidad para promover el diálogo profesor-alumno, y en el núm. 8, Comunicación, se jerarquizarán los aspectos afectivos que favorecen la negociación de ideas; y en el núm. 16, Autorregulación de su actuación, se relacionó no sólo con la autorregulación de futuros profesores sino también con la de sus alumnos. Finalmente se amplió el sentido del núm. 13, Evaluación, incidiendo más en el eco de compartir con los alumnos de los objetos y los criterios de evaluación.

\section{VALORACIÓN DE LOS RESULTADOS}

Los saberes «meta» que han puesto en juego las díadas en la resolución de la tarea encomendada encierran un tipo de conocimiento declarativo que implica, a su vez, la activación de conocimiento procedimental, de esquemas prácticos de acción en el aula y de aspectos afectivos.

Se puede inferir del análisis de las representaciones de ambas díadas que la situación de partida de la díada I es más favorable que la II. Ha activado conscientemente concepciones de enseñanza de la ciencia obtenidas no sólo a partir de la regulación realizada en función de los éxitos y fracasos derivados de su práctica, sino que les han dado sentido con aportes teóricos, indicándonos que tiene bastante interiorizado el modelo constructivista y las nuevas propuestas de la didáctica de las ciencias, así como prácticas cooperativas y de autorregulación.

En esta díada I parece existir más de una meta: la que persigue la tutora-investigadora de buscar referentes para que autogestionen sus aprendizajes y otra, más implícita y propia, la de lograr, como fin último, el aprendizaje significativo de sus alumnos a partir de transferir, entre otros, la propuesta de autorregulación a los mismos. Por el hecho de tratarse de una meta automotivada, inferimos que va a autodireccionar sus futuras actuaciones durante las prácticas docentes, va a ayudar y energizar su control y su evaluación, así como generar emociones positivas que a su vez influirán en sus futuras acciones.

En cambio, los saberes «meta» activados por la díada II reflejan varios obstáculos para el cambio, concepciones propias de un modelo de transmisión de los contenidos que hasta el momento se resisten a desautomatizarlo, así como la imposibilidad de los conocimientos pedagógicodidácticos que han recibido durante su formación con la práctica que van a iniciar.

Su acción parece obedecer sólo a metas externas, la que persigue la tutora-investigadora y la de la profesora de nivel medio, que no están embebidas de las necesidades del contexto específico de aprender a enseñar ciencias. Por ello inferimos que la díada II parece no identificar aún las metas y valores asociados a la propuesta de la tutora. Tales metas, por no ser automotivadas, podrían llegar a dificultar el aprendizaje autorregulado y a desencadenar emociones negativas en sus integrantes. Los formadores debemos tener en cuenta que lograr la autodeterminación de metas en estudiantes como los de la díada II representa una tarea muy difícil, pues se comportan más como autocontroladores acostumbrados a adoptar las metas de otros que como autorreguladores.

La díada I parecería estar más preparada para hacer lo que ellas quieren, para tener control de sus cambios y para saber cómo utilizar sus propios recursos a fin de 
autorregular su aprendizaje. En cambio, de la II podemos esperar que hagan lo que ellas mismas piensan que se espera de ellas y que busquen una regulación externa, de la tutora o de la profesora del aula.

Aunque supusimos que los resultados más alentadores de la díada I sobre la II se podrían deber al desarrollo del componente dinámico de sus integrantes expertas, la hipótesis se desbarata con los pobres resultados de Marcela, integrante de la II, también experta, y con los muy satisfactorios de la experiencia piloto 98 llevada a cabo con novatas. Por lo tanto, el componente profesional dinámico no sería la variable que determinaría el comportamiento más innovador de la díada I ni tampoco la que evita los rasgos y las actuaciones más tradicionales en la experta Marcela.

Las díadas y la tutora valoran, en sus objetos, múltiples y diversos aspectos a autorregular del aprender a enseñar ciencias, que en muchos casos coinciden. Sin embargo, corroboramos que pueden subyacer significados diferentes acerca de los mismos y que no es obvio, y sí un proceso complejo, el aprendizaje en grupos cooperativos que conduzcan a verdaderos consensos, especialmente cuando una de las partes es un experto, y más aún si ese experto es la profesora que las ha de evaluar.

Consideramos que los procesos de negociación estuvieron influidos, según el caso, por diferentes dinámicas emocionales. Así, el de la díada I se caracterizó por la intersubjetividad (Trevarthen, 1982) alcanzada entre sus integrantes, producto de trabajar juntas durante muchos años; en cambio, el de la II y el de las díadas con la tutora, por relaciones asimétricas de poder determinadas por el desarrollo del componente dinámico de las expertas frente a las novatas, resultado que se debería contemplar en el momento de constitución de parejas de trabajo.

Desde la propia autorregulación de la tutora-investigadora, se ve muy necesario dedicar más tiempo a la creación efectiva de una zona de negociación (Leontiev, 1983), ya que se dieron muchos sobreentendidos que impidieron la verdadera socialización cognitiva de los criterios de evaluación a través del lenguaje. Sin embargo, consideramos que la metodología puesta en juego en el compartir objetos y criterios de evaluación representa una importante actividad de modelamiento metacognitivo (Monereo y Badía, 1997). Se crean contextos potentes de aprender a enseñar ciencias (o de aprender a aprender) que ayudan a transformar lo implícito y tácito en explícito y consciente; a intercambiar conocimientos entre pares, a engendrar más saberes metacognitivos en los estudiantes.

Esperamos, a través del análisis de los restantes instrumentos que recogieron los resultados de aplicar los objetos y criterios en cuestión durante las prácticas docentes, llegar a caracterizar los distintos niveles metacognitivos y metaafectivos que parecen atravesar cada una de nuestras estudiantes, así como profundizar en nuestro modelo de formación inicial (y permanente) de profesores, especialmente en relación con los aspectos afectivos.

\section{REFERENCIAS BIBLIOGRÁFICAS}

ANGULO, F. (1996). «Aprender a enseñar ciencias. Análisis de la aplicación de una propuesta basada en la autorregulación de los aprendizajes». Tesis de maestría. Barcelona: Universitat Autònoma de Barcelona.

ANGULO, F. (2002). Aprender a enseñar ciencias. Análisis de una propuesta para la formación inicial del profesorado de secundaria, basada en la metacognición». Tesis doctoral. Barcelona: Universitat Autònoma de Barcelona.

ANGULO, F. y GARCÍA, P. (1996). La autorregulación de los aprendizajes: una estrategia para la formación del profesorado. Alambique, 9, pp. 91-101.

ANGULO, F. y GARCÍA, P. (2001). La interacción social como motor de la metacognición. Actas Congreso Nacional de Didácticas Específicas. Grupo Editorial Universitario II, pp. 549-1560.

ASTOLFI, J.P. y PATERFALVI, B. (1997). Stratégies de travail des obstacles: dispositifs et ressorts. Aster, 25.
BAIRD, J., FENSHAM, P. y GUNSTONE, R. (1991). The importance of reflection in Improving Science teaching and learning. Journal of Research in Science Teaching, 28(2) pp. 163-182.

BAIRD, J. y NORTHFIELD, J. (1992). Learning from the Peel experience. Australia: Monash University Printing Service.

BIZQUERRA, R. (2000). Educación emocional y bienestar. Barcelona: Praxis.

BOEKAERTS, M. (1995). Self-regulated learning Bridging the gap between metacognitive and metamotivation theories. Educational Psychologist, 3(4), pp. 195-200.

BOEKAERTS, M. (1999). Motivated learning. The study of student x situation transactional units. European Journal of Psychology of Education, 14(4), pp. 41-45.

BROWN (1987). Metacognition, Executive Control, Selfregulation and Other More Mysterious Mechanisms, en 
Weinert, F.E. y Kluwe, R.H. Metacognition, motivation and understanding. Nueva York: Hellsdale.

BUTLER, D. y WINNE, P. (1995). Feedback and self-regulated learning. A theoretical synthesis. Review of Educational Research, 64(3), pp. 245-281.

CORNO, L. (1994). «Implicit teachings and self-regulated learning». Comunicación presentada en el Annual Meeting of the American Educational Research Association. New Orleans, L A. 4-8 de abril.

COPELLO, L. (1998). «Formación permanente del profesorado de biología centrada en la reflexión dialógica sobre el trabajo cotidiano en el aula». Tesis doctoral. Universitat Autònoma de Barcelona.

COPELLO, L. y SANMARTÍ, N. (2001). Fundamentos de un modelo de formación permanente del profesorado de ciencias centrada en la reflexión dialógica sobre las concepciones y las prácticas. Enseñanza de las Ciencias, 19(2), pp. 269-283.

DECI y RYAN, R. (1985). Intrinsic motivation and self determination in human behavior. Nueva York: Plenum.

EDWARDS, D. y MERCER, N. (1987). El conocimiento compartido. El desarrollo de la comprensión en el aula. Madrid: Paidós.

FLAVELL, J.H. (1976). Metacognitive aspects of problem solving, en Resnick, I.B. (ed.). The nature of intelligence, pp. 231-235. Hillsdake, NJ: Erlbaum.

FLAVELL, J.H. (1987). Speculations about the nature and development of metacognition, en Weinert, E., Khuwe, R. (eds.). Metacognition, motivation and understanding. Hillsdale, N.J.: Erlbaum.

FURIÓ, C. (1994). Tendencias actuales en la formación del profesorado de ciencias. Enseñanza de las Ciencias, 12(2), pp. 188-199.

GAHATALA, E.S., LEVIN, J.R., FOORMAN, B.R. y PRESSLEY, M. (1989). Improving children's regulation of their reading PREP time. Contemporary Educational Psychology, 14, pp. 49-66.

GARNER, R. (1987). Metacognition and reading comprehension. Norwood, N.J.: Ablex.

GUESS-NEUSOME, J. y LEDERMAN, N. (1993). Preservice biology teacher's knowledge structures as a function of professional teacher education. A year-long assessment. Science Education, 77(1), pp. 25-45.

GUNSTONE, R. y NORTHFIELD, J. (1994). Metacognition and learning to teach. Journal Science Education, 16(5), pp. 523-537.

GUNSTONE, R., BAIRD, J. y NORTHFIELD, J. (1993). A case study exploration of development in preservice science teachers. Science Education, 77(1), pp. 47-73.

GUNSTONE, R.F. y MITCHELL, I.J. (1998). Metacognition and Conceptual Change, en Mintzes, J.J., Wandersee, J.H., Novak, J.D. Teaching Science for Understanding. A Human Constructivist View, pp. 133-163. Londres.

GUNSTONE, R. (2000). «The Education of Teachers of Physics: Contents plus Pedagogy plus Reflective Practice».
Comunicación presentada PHYTEB 2000. Physics Teacher Education beyond 2000. Barcelona.

HEWSON, P.W., TABACHNICK, B.R., ZEICHNER, K. M., BLOMKER, K.B., MEYER, H., LEM-BERGER, J., MARION, R., PARK, H. y TOOLIN, R. (1999). Educating Prospective Teacher of Biology: Introduction and Research Methods. Science Education, 83(3), pp. 247-274.

HUGO, D. (1998). Una experiencia piloto de autorregulación basada en la elaboración de objetos y criterios de evaluación por futuros profesores de ciencias. Barcelona: Universitat Autònoma de Barcelona. (Trabajo no publicado).

HUGO, D. (2000). «Compartiendo objetos y criterios de evaluación con futuras profesoras de ciencias». Tesis de mestría. Barcelona: Universitat Autònoma de Barcelona. (Trabajo no publicado).

JORBA, J. y SANMARTÍ, N. (1995). Autorregulación de los procesos de aprendizaje y construcción de conocimientos. Alambique, 4.

JOSHUA, S. y DUPIN, J.J. (1993) Introduction à la didactique des sciences et des mathématiques. París: PUF.

KEHR, H., BLES, P. y ROSENTIEL, L. (1999). Selfregulation, self-control and management training transfer. International Journal of Educational Research, 31, pp. 487-498.

LEDERMAN, N.G., GESS-NEWSOME, J. y LATZ, M.S. (1994). The Nature and Development of Pre-service Science Teachers' Conceptions of Subject Matter and Pedagogy. Journal of Research in Science Teaching, 31(2), pp. 129-146.

LEONTIEV, A. (1983). El desarrollo del psiquismo. Madrid: Akal Universidad.

LINDER, R.H. y HARRIS, D. (1992). «Self-regulated learning and academic achievement in college students». Comunicación presentada en American Educational Research Association Annual Meeting. 20-24 de abril. San Francisco, CA.

LUCIO, R. (2002). «La actividad metacognitiva como desencadenante de procesos autorreguladores en las concepciones y prácticas de enseñanza de los profesores de ciencias experimentales». Tesis doctoral. Barcelona: Universitat Autònoma de Barcelona.

MARCELO, C. (1994). Investigaciones sobre prácticas en los últimos años: qué nos aportan para la mejora cualitativa de las prácticas, en Montero, M.I., Cebreiro, B. y Zabala, M. A. (eds.). El practicum en la formación de profesionales: problemas y desafíos. Santiago: Tórculo.

MELLADO, V., BLANCO NIETO, L., RUIZ MACÍAS, C. (1999). Aprender a enseñar ciencias experimentales en la formación inicial del profesorado. Badajoz: Universidad de Extremadura (ICE).

MELLADO, V. (1996). Concepciones y prácticas de aula de profesores de ciencias, en formación inicial, de primaria y secundaria. Enseñanza de las Ciencias, 14(3), pp. 302-398.

MONEREO, C. y BADÍA, C.B. (1997). Las estrategias de aprendizaje. Barcelona: Edebé 
NELSON, T.O. y NARENS, L. (1990). Metamemory: A theoretical framework and some new findings, en Bower, G.H. (ed.). The psychology of learning and motivation, 26, pp. 125-173. San Diego: Academic Press.

NELSON, T.O. y NARENS, L. (1994). Why investigate metacognition?, en Metcalfe, J. y Shimamura, A.P. (eds.). Metacognition: Knowing about knowing, pp. 1-25. Cambridge, MA: MIT Press.

NUNZIATI, G. (1990). Pour construire un Dispositif dévaluation Formatrice. Cahiers Pedagogiques, 280, pp. 47-64.

PORLÁN, R., RIVERI, G. y MARTÍN DEL POZO, R. (1997). Conocimiento profesional y epistemología de los profesores I: teoría, métodos e instrumentos. Enseñanza de las Ciencias, 15(2), pp. 155-171.

PORLÁN, R. (2001). La formación de profesores de secundaria: principios para una nueva formación inicial. Actas del Congreso Nacional de Didácticas Específicas. Granada.

POZO, J.I. (1999). Más allá del cambio conceptual: el aprendizaje de las ciencias como cambio representacional. Enseñanzas de las Ciencias, 17(3), pp. 413-520.

PRINTICH, P.R., SMITH, D.A., F. GARCÍA, T. y McKEACHIE, W. (1993). Reliability and predictive validity of the Motivated Strategies for Learning Questionnaire (MSLQ). Educational and Psychological Measurement, 53, pp. 801-813.

SANMARTÍ, N. (2000). «Aprender una nueva manera de pensar y de aplicar la evaluación: un reto en la formación inicial del profesorado». Simposio sobre la Formación Inicial de los Profesionales de la Educación, pp. 321-345. Girona: Universitat de Girona.

SANMARTÍ, N. (2001). Enseñar a enseñar ciencias en secundaria: un reto muy complejo. Revista Interuniversitaria de Formación del Profesorado, 40, pp. 31-48.

SWANSON, H.L. (1990). Influence of metacognitive knowledge and actitude on problem-solving. Journal of Educational Psychology, 82, pp. 306-314.

TOBIN, K. (1993). Referents for making sense of science teaching. International Journal of Science Education, 15(3), pp. 241-254.

TREVARTHEN, C. (1982). The primary motives for cooperative understanding, en Butterwood, G. y Light, P. (comps.). Social cognition. Studies of the development of understanding. Chicago: The University of Chicago Press.

WERTCH, J. (1981). Language and cognition. Washington: Winston and Sous.

WHITE, B.Y. (1999). Condiciones para un aprendizaje de calidad en la enseñanza de las ciencias. Enseñanza de las Ciencias, 17(1), pp. 3-16.

ZIMMMERMAN, B.J. y SCHUNK, D.H. (eds.) (1989). Selfregulated Learning and Academic Achievement. Nueva York: Springer-Verlag.

ZIMMERMAN, B.J. (1999). Attainment of self-regulation: A social cognitive perspective, en Boekaerts, M., Pintrich, P., Seidner, M. Self regulation: Theory, research and applications. Orlando, FL: Academic Press. 


\section{ANEXO}

Objetos y criterioS de evaluación negociados por las díadas I y II

\begin{tabular}{|c|c|}
\hline Objetos de la díada I (Analía y Mari) & Criterios de evaluación \\
\hline • Relación con los alumnos. & \multirow{2}{*}{$\begin{array}{l}\text { - Desde lo afectivo en el diálogo, en gestos, en el clima que reine } \\
\text { en el aula. } \\
\text { - Desde lo coginitivo en la capacidad para motivar, despertar } \\
\text { el interés. }\end{array}$} \\
\hline • Claridad conceptual en las explicaciones. & \\
\hline $\begin{array}{l}\text { - Lenguaje utilizado, que ayude a comprender lo que se habla } \\
\text { y a enriquecer el que se tiene. }\end{array}$ & $\begin{array}{l}\text { - En el desarrollo de la clase, en la interacción con los alumnos } \\
\text { (la capacidad de generar preguntas en ellos y poder dar respuestas). }\end{array}$ \\
\hline $\begin{array}{l}\text { - El material empleado, que sea de lectura comprensible con ejercita- } \\
\text { ción de acuerdo con sus capacidades. }\end{array}$ & - La complejidad que presente la resolución de los trabajos. \\
\hline $\begin{array}{l}\text { - La selección de contenidos } \\
\text { (el nivel de pofundidad con que se desarrollan). }\end{array}$ & $\begin{array}{l}\text { - Que estén relacionados con la vida cotidiana y les sirvan para inter- } \\
\text { pretar los fenómenos que viven. }\end{array}$ \\
\hline • La autorregulación. & $\begin{array}{l}\text { - Si se logra que todos podamos controlar nuestros aprendizajes: } \\
\text { «Qué y cómo aprendemos?». }\end{array}$ \\
\hline - El manejo del tiempo en la planificación. & $\begin{array}{l}\text { - Que los contenidos y las actividades sean acordes con el tiempo } \\
\text { que se tiene. }\end{array}$ \\
\hline
\end{tabular}

\begin{tabular}{|c|c|}
\hline Objetos díada II (Josefa y Marcela) & Criterios de evaluación \\
\hline - Relación con los alumnos. & $\begin{array}{l}\text { - Si conseguimos establecer una relación amena y respetuosa, } \\
\text { de mutua confianza. }\end{array}$ \\
\hline - Desarrollo de la clase. & $\begin{array}{l}\text { - Si conseguimos explicar claramente los contenidos, utilizando co- } \\
\text { rrectamente el lenguaje y con ejemplos adecuados. }\end{array}$ \\
\hline - Estructuración de la unidad a innovar (guión didáctico). & $\begin{array}{l}\text { - Presentación, secuenciación, organización, claridad, profundidad } \\
\text { en el tratamiento del tema y coherencia de actividades. }\end{array}$ \\
\hline - Utilización del espacio, del tiempo y de los recursos. & $\begin{array}{l}\text { - Si conseguimos manejar bien el espacio del pizarrón con expresiones } \\
\text { legibles, ordenadas y prolijas. } \\
\text { - Si administramos adecuadamente el escaso tiempo de una época } \\
\text { y de cada clase. }\end{array}$ \\
\hline - Cumplimiento de los objetivos propuestos. & $\begin{array}{l}\text { - Si al final de la práctica logramos alcanzar los objetivos generales } \\
\text { de la asignatura propuestos por la profesora titular. }\end{array}$ \\
\hline - Creatividad y originalidad. & $\begin{array}{l}\text { - Si el tipo de ejercitación, evaluación y actividades resultan atractivas } \\
\text { y motivadoras para los alumnos. }\end{array}$ \\
\hline
\end{tabular}




\author{
ANEXO \\ Objetos y criterios de evaluación de la tutora-investigadora
}

\title{
1. Planificación
}

- Tiene previstos, en la planificación o en el guión didáctico, los momentos de los ciclos de aprendizaje, la secuenciación de los contenidos y aspectos bien diversos del trabajo en el aula desde los objetivos que persigue; prevé qué hará, qué preguntará, qué ha de tener presente; una buena variedad de actividades; qué y cómo evaluará.

\section{Conocimiento del tema}

- Demuestra tener información suficiente y adecuada sobre el tema que ha de desarrollar.

\section{Preparación del material}

- Ha pensado, a través del guión didáctico, en aquello que los alumnos han de hacer, en todo lo que necesitan para realizar las actividades. El guión didáctico a trabajar con los alumnos es motivador, bien presentado y gramaticalmente correcto.

\section{Gestión del aula (capacidad para organizar el trabajo del alumno)}

- Prevé la organización del trabajo de los alumnos y combina momentos de trabajo individual, en grupos y en grupo clase. Da instrucciones claras y argumentadas sobre qué han de hacer los alumnos y cómo han de hacerlo, controla bien el tiempo, etc. Estimula la realización de trabajos y tiene en cuenta las opiniones de los estudiantes.

\section{Control de clase}

- Mantiene el control de la clase durante gran parte del tiempo y un buen ritmo del trabajo del alumnado, del interés y de la participación. Sabe cambiar de actividad cuando el grupo manifiesta un cierto cansancio. Afronta las situaciones adversas buscando nuevas soluciones.

\section{Comunicación}

- Es fácil entenderle y se da cuenta cuando los estudiantes no le entienden. Utiliza un tono de voz y gesticulaciones adecuadas, mira a los alumnos, es convincente.

\section{Capacidad para promover el diálogo profesor-alumno}

- Programa que todos los estudiantes intervengan y tiene en cuenta sus respuestas, aciertos y errores.

\section{Atención a la diversidad}

- Prevé actividades diversificadas, formas organizativas o materiales diversos para atender la diversidad de los alumnos. Piensa en la diversidad de concepciones y de prerrequisitos que tienen o necesitan los alumnos al inicio de un tema así como los procedimientos de trabajo, de actitudes y de intereses.

\section{Visión globalizada de la actividad educativa (visión del colegio)}

- Establece nexos con otras materias del área que cursan o han cursado los alumnos. Se interesa por los intereses, características y problemas de los alumnos. Contextualiza su programación. Intenta responder a las necesidades detectadas. Incluye aspectos relacionados con otros temas transversales del currículo.

\section{Uso del pizarrón}

- No abusa de su uso; escribe ordenada y claramente de izquierda a derecha; pone información relevante.

\section{Capacidad para organizar el trabajo experimental en el laboratorio}

- Prepara guiones de trabajo adecuados; relaciona teoría-práctica; adecua el trabajo a nivel de los alumnos; organiza bien el trabajo de los grupos pequeños y del grupo clase; el material necesario y el tiempo previsto; las normas de trabajo. Diversifica algunas partes del trabajo. Comunica bien los objetivos del trabajo y cómo lo han de trabajar en el tiempo previsto.

\section{2 . Uso de recursos audiovisuales (modelos, CD, vídeos, software)}

- Los recursos presentan la información de manera adecuada al tema de trabajo, clara e interactiva. Cuando la información es compleja y relevante, prevé que los alumnos dispongan a tiempo de material de apoyo. Tiene en cuenta su duración y si es adecuada al nivel de los alumnos y a la fase del proceso de aprendizaje. Prevé el conocimiento por parte del alumno del vocabulario específico o la necesidad de introducirlo. Prevé qué van a hacer los estudiantes antes y después de su uso.

\section{Evaluación}

- Prevé y concretiza cómo y a través de qué evaluar el proceso de aprendizaje en instancias de coevaluación o evaluación mutua o autoevaluación que promuevan la autorregulación del aprender a aprender ciencias. Explicita los objetos y criterios de evaluación para la autorregulación de los procesos de aprendizaje de toda la unidad o de ciertas actividades en particular. Contempla tanto aspectos conceptuales como procedimentales y actitudinales. Se tienen en cuenta en la evolución de los alumnos y no sólo en el examen final. 


\section{Actitud global}

- Se ha dedicado a fondo al trabajo, ha explicitado sus puntos de vista, ha intentado conocer a los alumnos y al colegio, trabaja cooperativamente con sus pares, tutora y profesora del curso. Demuestra ser innovador.

\section{Didáctica innovadora}

- Incorpora nuevos aportes de la investigación en didáctica de las ciencias, como la historia y la epistemología; selecciona contenidos desde la CTS incorporando contenidos transversales; los organiza con enfoque globalizador; trabaja a través de las concepciones del estudiantado; problematiza los contenidos; implementa metodología de proyectos y actividades para que sus alumnos «aprendan a aprender», etc.

\section{Autorregulación de su actuación}

- Aplica los objetos y criterios consensuados con el otro integrante de su díada y la tutora para autorregular su aprender a enseñar. Reconoce errores o falencias y propone cómo superarlos. Escucha sugerencias de la tutora, la profesora del curso y pares. Modifica su actuación en función de sus reflexiones y sugerencias. 